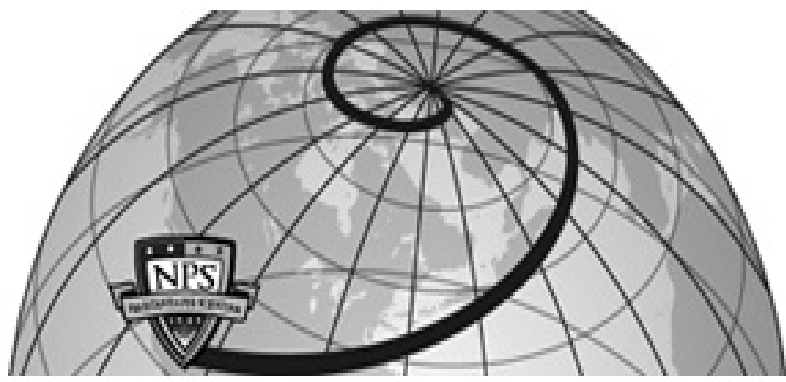

Calhoun: The NPS Institutional Archive DSpace Repository

\title{
Non-cylindrical mine drop experiment
}

\author{
Chu, Peter C.; Allen, Charles; Fleischer, Peter
}

Chu, P.C., C. Allen, and P. Fleischer, 2006: Non-cylindrical mine impact experiment.

Seventh Monterey International Symposium on Technology and Mine Problems, Society for Counter-Ordnance Technology, Monterey, California, DVD-ROM, 10 pages https://hdl.handle.net/10945/36275

This publication is a work of the U.S. Government as defined in Title 17, United States Code, Section 101. Copyright protection is not available for this work in the United States.

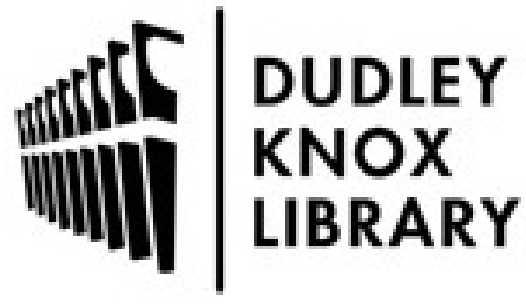

http://www.nps.edu/library
Calhoun is the Naval Postgraduate School's public access digital repository for research materials and institutional publications created by the NPS community. Calhoun is named for Professor of Mathematics Guy K. Calhoun, NPS's first appointed -- and published -- scholarly author.

Dudley Knox Library / Naval Postgraduate School 411 Dyer Road / 1 University Circle Monterey, California USA 93943 


\title{
Non-Cylindrical Mine Drop Experiment
}

\author{
Dr. Peter C. Chu and LT Charles Allen \\ Naval Ocean Analysis and Prediction Laboratory, Naval Postgraduate School, Monterey CA 93943 \\ Dr. Peter Fleischer
}

Naval Oceanographic Office, Stennis Space Center, MS 39529

\begin{abstract}
The Navy's Impact Burial Model (IMPACT35) predicts the cylindrical mine trajectory in air and water columns and burial depth and orientation in sediment. Impact burial calculations are derived primarily from the sediment characteristics and from the mine's threedimensional air and water phase trajectories. Accurate burial prediction requires that the model's water phase trajectory reasonably mimics the object's true trajectory. In order to determine what effect varying the shape to more closely match real-world mines has on the shape's water phase trajectory, Mine Drop Experiment II was conducted. The experiment consisted of dropping four separate types of shapes into a water column, and the resultant falls were filmed from two nearly orthogonal angles. Initial drop position, initial velocities, and the drop angle were controlled parameters. Observed trajectories were highly variable, but several broad conclusions were reached: the Manta and Rockan shapes' trajectories were much more complex than the Sphere and Gumdrop trajectories; the denser Gumdrop shape had the fastest and straightest drops overall to $-250 \mathrm{~cm}$ depth; because of important factors, the dispersion of all four shapes was wide and variable. The data collected from the experiment can be used to develop and validate the mine Impact Burial Prediction Model with operational, non-cylindrical mine shapes.
\end{abstract}

\section{Introduction}

The end of the Cold War marked a shift for the U.S. Navy from "blue" water, anti-Soviet focus, towards a concentration on the regional littoral threats of the world. With the increasing number of regional and asymmetric threats, the Navy must operate effectively and safely in near-shore waters. A grave threat in this operating theater is the sea mine.

Though mines have been part of naval warfare since ancient Greece, they have challenged U.S. naval power for over 200 years. Due to their low cost, ease of deployment, and uncompromised effectiveness, mines are a highly sought force multiplier. Whether used offensively to mine enemy harbors or shipping lanes or defensively against amphibious assault, mines can deal large amounts of damage for minimal cost and no loss of life for those employing them. Since 1946, at least 14 U.S. ships, including two in the first Gulf War, have been damaged or sunk by small-scale mining operations. An Iranian SADAF-02 contact mine, costing only $\$ 1500$, hit and nearly sank the Samuel B. Roberts (FFG-58) in 1988, costing almost $\$ 96$ million in damages (MWP, 2006).

Today at least 45 countries (including the United States and countries comprising the former Soviet Union) possess mining capability, and many more nations can acquire that capability very quickly. Over 20 countries produce mines, and 13 are confirmed mine exporters. In addition, an unknown threat exists as virtually any country or properly funded terrorist organization can effectively produce a mine (Baciocco, 1997).

Significant challenges still remain in the surveillance, reconnaissance, detection, and neutralization of mines. The sheer variety of the mine threat does not allow a single solution in the MCM equation. The primary challenge is to determine exactly where the waiting mines are located, and the primary factor that can ease or hinder the search for those mines is the bathymetric character of the sea bottom. High bottom clutter including rock outcroppings, coral reefs, or man-made debris or structures, gives many false alarms or shadow zones that increase overall MCM clearance times. Figure 1 shows the many depths and types of mines used in the littoral environment.

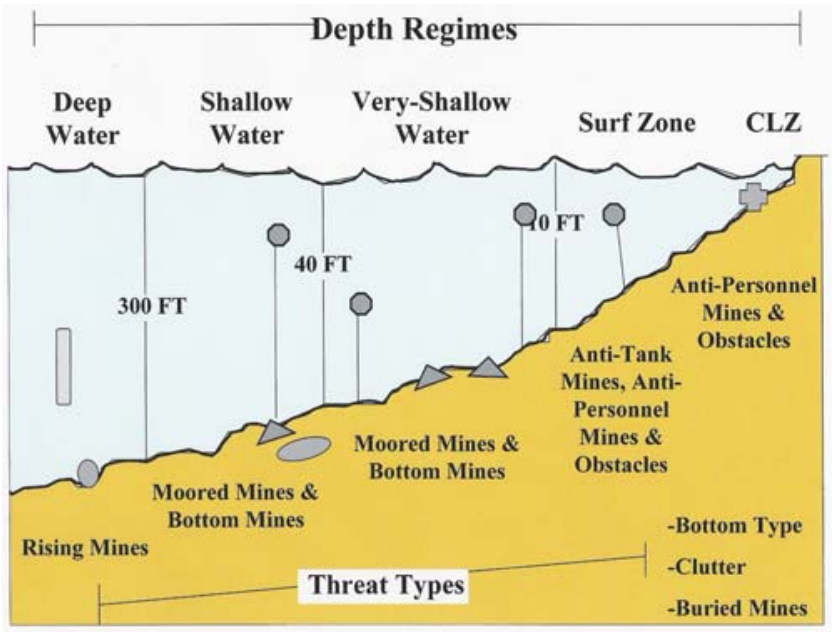

Figure 1. Depth Regimes for Littoral Mine Warfare (After MWP, 2006). 
However, attempting to obtain accurate data of potential enemy shores may not be easy, so MCM plans must account for this uncertainty. Models used to formulate impact burial (IB) sites of dropped bottom mines have thus been developed to counter that uncertainty. Using those models, the planner can, when knowing the release position of the mine above the surface, predict the mine's vertical position in the air and water to ultimately determine the burial depth in the sea sediment.

The one-dimensional Impact Burial Prediction Model (IBPM), developed by Arnone and Bowen in 1980, was able to predict the vertical position of a cylindrical mine's center of mass (COM) through air, water, and sediment. The burial depth was based on the mine's velocity at sediment depth as well as the properties of the sediment. Satkowiak (1988) added additional modeling and mathematical complexity, but the major weakness of the one-dimensional model, the assumption of a constant mine orientation as it falls, remained.

Two-dimensional models were developed to overcome this limitation (Hurst, 1992). The two versions, IMPACT 25 (written in BASIC) and IMPACT 28 (written in BASIC and Matlab), contained two momentum equations (in $\mathrm{X}$ - and z-directions) and a moment of momentum equation (in the $y$-direction). Thus it was able to predict the mine's COM position in the $\mathrm{x}-\mathrm{z}$ plane and the rotation about the $\mathrm{y}$-axis. Sensitivity studies on the two-dimensional model (Taber, 1999) indicated that mine burial depth was not affected by the mine releasing height. Another experiment in Monterey Bay (Chu et al., 2004; 2005) showed IMPACT 25 overpredicted burial depth. The primary weakness of the twodimensional model, however, was that is was very difficult to include fluid motion, as any fluid motion in the y-axis broke the two-dimensional plane.

The latest IBPM is IMPACT 35. With full physics, the model contains three momentum equations and three momentum equations, predicting the mine's COM position in $(\mathrm{x}, \mathrm{y}, \mathrm{z})$ space and the rotation around all three axes (Chu et al., 2002; 2003; 2004). Testing and evaluation of IMPACT 25 and IMPACT 35 at the Naval Surface Warfare Center-Carderock, Corpus Christi, and the Baltic Sea (Valent et al., 2002; Holland et al., 2004; Elmore et al., 2004) has shown significant improvement of threedimensional modeling over two-dimensional.

The main limitation of the current iteration of IMPACT 35 is its utilization for cylindrical mines only. The effect of shape is a significant issue if the model is to be used operationally, as the most widely-used bottom mines such as the Manta and the Rockan are not cylindrical. Determination of the hydrodynamic force and torque for non-cylindrical mines is crucial. Conformal projection may be used to transfer a non-cylindrical mine into an equivalent cylindrical mine, with chaotic features being handled with instability and predictability analyses.
Overcoming IMPACT 35's weakness requires test data involving various shapes. MIDEX II, conducted in September 2005, is the direct continuation of this testing and data gathering process. In that experiment, the overall shape of the mine was varied from the IMPACT 35 cylinder to see how the water phase trajectory would be affected. In addition to a Sphere and semi-hemispherical "Gumdrop" shape, two shapes were specifically chosen to represent real world bottom mines: the Manta and Rockan.

The Manta (Figure 2a) is an anti-invasion bottom mine, produced primarily by the Italian firm Whitehead Alenia. It is shaped as a truncated cone with a glass reinforced plastic (GRP) casing, triggered either acoustically or magnetically. The Manta has a shelf life of 30 years and will operate for 17 months after activation. Sweden's acoustic and magnetic BGM-100 Rockan mine (Figure 2b) has a gliding shape which allows mine-laying over a wide area while covering the minimal distance; its low-profile stealth shape makes it difficult to detect. Its casing is also constructed of GRP. Both the Manta and Rockan are made even stealthier by having anechoic coatings and being made of nonferrous materials to reduce the mines' acoustic and magnetic signatures. Tables 1 and 2 show the physical parameters of Rockan and Manta mines.

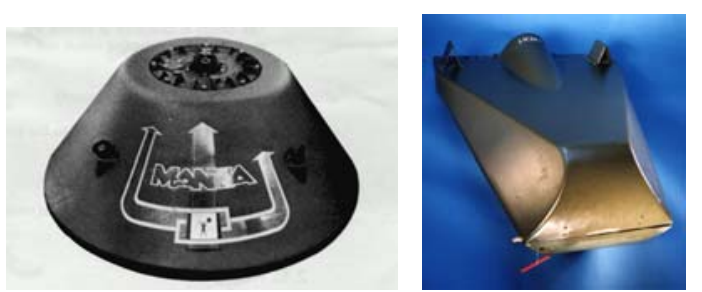

Figure 2. Popular mines: (a) Rockan, and (b) Manta.

Table 1. Physical parameters of Rockan mines.

\begin{tabular}{|l|l|}
\hline Diameter & $0.980 \mathrm{~m}$ \\
\hline Height & $0.440 \mathrm{~m}$ \\
\hline Weight & $220 \mathrm{~kg}$ \\
\hline Charge & $130 \mathrm{~kg}$ (HBX-3) \\
\hline $\begin{array}{l}\text { Operatin } \\
\text { g Depth }\end{array}$ & $3-100 \mathrm{~m}$ \\
\hline
\end{tabular}

Table 2. Physical parameters of Manta mines.

\begin{tabular}{|l|l|}
\hline Length: & $1.015 \mathrm{~m}$ \\
\hline Width: & $0.800 \mathrm{~m}$ \\
\hline Height: & $0.385 \mathrm{~m}$ \\
\hline Weight: & $190 \mathrm{~kg}$ \\
\hline Charge: & $105 \mathrm{~kg}$ (Cemtex) \\
\hline $\begin{array}{l}\text { Operating } \\
\text { Depth: }\end{array}$ & $105 \mathrm{~kg}$ \\
\hline
\end{tabular}

\section{Hydrodynamics of Rigid Body Movement in} Fluids 
Study on the movement of a rigid body in fluid has wide scientific significance and technical application. It involves nonlinear dynamics, flight theory, body-fluid interaction, and instability theory (von Mises, 1959). Prediction of a falling rigid body in the water column is a key component in determining the impact speed and direction of mine on the sediment and in turn in determining its burial depth and orientation.

\section{A. Triple Coordinate Systems}

Consider two three-dimensional shapes based on the Manta and Rockan mines with the center of mass (COM) $\mathbf{X}$ and center of volume (COV) $\mathbf{B}$ on the main axis (Figures 3 and 4). Let $(L, d, \chi)$ represent the mine's length, width, and the distance between the two points $(\mathbf{X}, \mathbf{B})$. The positive $\chi$-values refer to nose-down case, i.e., the point $\mathbf{X}$ is lower than the point B. Three coordinate systems are used to model the falling shape through the air, water, and sediment phases: earth-fixed coordinate (E-coordinate), main-axis following coordinate (M-coordinate), and force following coordinate (F-coordinate) systems. All the systems are three-dimensional, orthogonal, and righthanded. The origin of $\mathbf{M}$ - and F-coordinates is located at $\mathbf{X}$ (Chu et al., 2004).

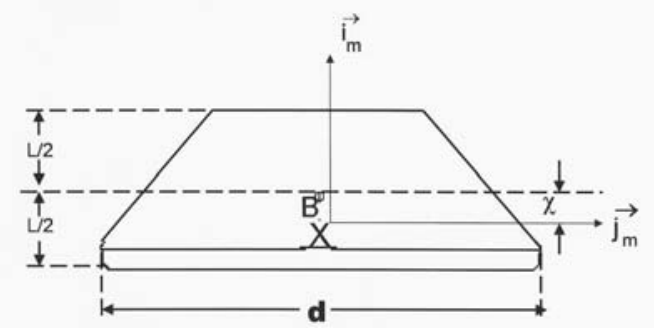

Figure 3. M-coordinate with the COM as the origin $\mathrm{X}$ and $\left(\mathrm{i}_{\mathrm{m}}\right.$, $\mathrm{j}_{\mathrm{m}}$ ) as the two axes. Here, $\chi$ is the distance between the $\mathrm{COV}$ (B) and COM, $(L, d)$ are the shape's length and diameter.

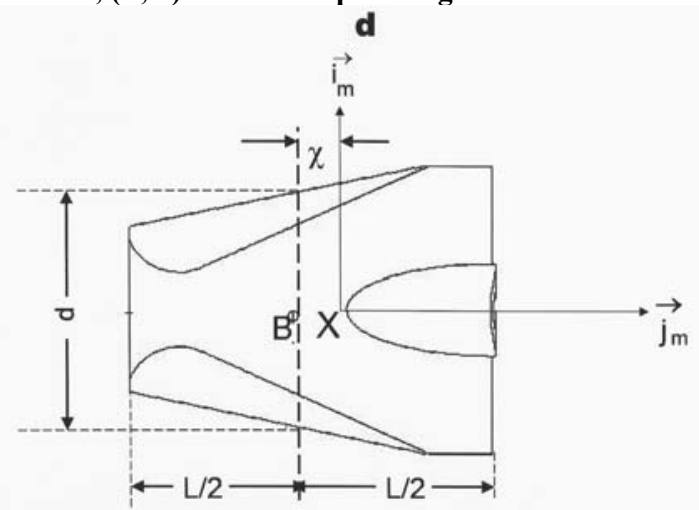

Figure 4. M-coordinate with the $C O M$ as the origin $X$ and $\left(i_{m}\right.$, $\mathbf{j}_{\mathrm{m}}$ ) as the two axes. Here, $\chi$ is the distance between the $\mathrm{COV}$ (B) and COM, $(L, d)$ are the shape's length and diameter.

The E-coordinate is represented by $\mathrm{F}_{\mathrm{E}}(\mathrm{O}, \mathrm{i}, \mathrm{j}, \mathrm{k})$ with the origin ' $\mathrm{O}$ ', and three axes: $x$-, $y$ - axes (horizontal) with the unit vectors (i, $\mathrm{j}$ ) and $\mathrm{z}$-axis (vertical) with the unit vector $\mathrm{k}$ (upward positive) (see Figures 5 and 6). The position of the shape is represented by the COM position,

$$
\mathbf{X}=x \mathbf{i}+y \mathbf{j}+z \mathbf{k} \text {. }
$$

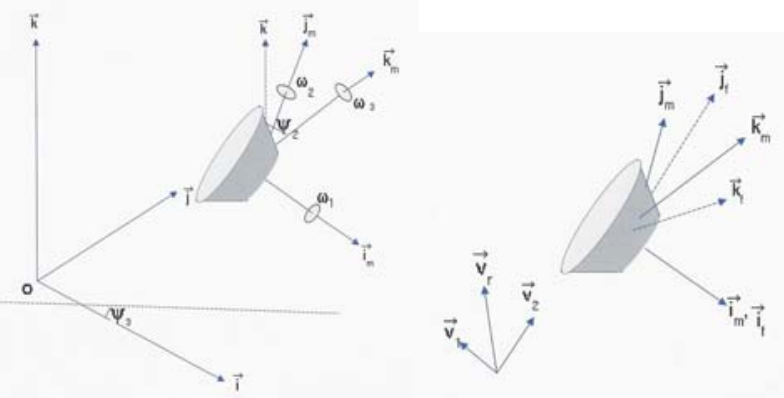

Figure 5. Three coordinate systems for Manta shape.
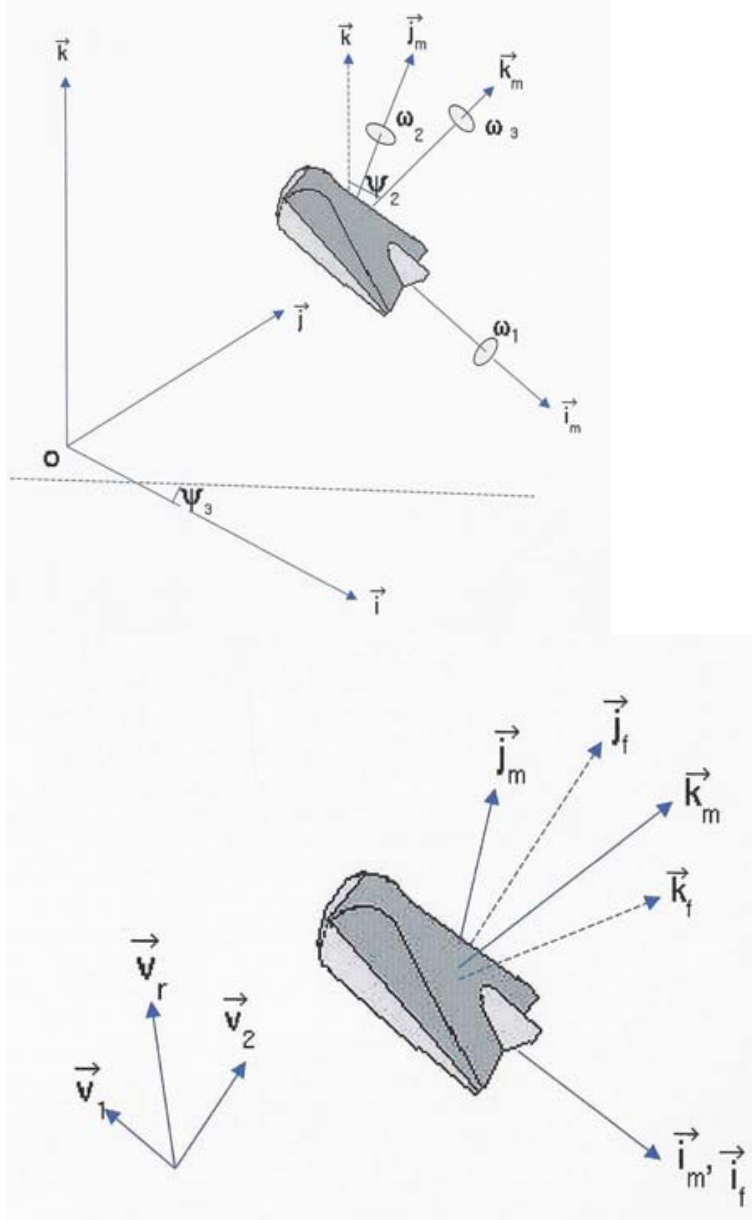

Figure 6. Three coordinate systems for Rockan shape.

The translation velocity is given by

$$
\frac{d \mathbf{X}}{d t}=\mathbf{V}, \quad \mathbf{V}=(u, v, w)
$$


The orientation of the mine's main-axis (pointing downward) is given by $\mathbf{i}_{\mathrm{M}}$. The angle between $\mathbf{i}_{\mathrm{M}}$ and $\mathbf{k}$ is denoted by $\psi_{2}+\pi / 2$. Projection of the vector $\mathbf{i}_{\mathrm{M}}$ onto the $(x, y)$ plane creates angle $\left(\psi_{3}\right)$ between the projection and the $x$-axis (Figures 5 and 6). The M-coordinate is represented by $\mathrm{F}_{\mathrm{M}}\left(\mathrm{X}, \mathbf{i}_{\mathrm{M}}, \mathbf{j}_{\mathrm{M}}, \mathbf{k}_{\mathrm{M}}\right)$ with the origin ' $\mathrm{X}$ ', unit vectors $\left(\mathrm{i}_{\mathrm{M}}, \mathrm{j}_{\mathrm{M}}, \mathrm{k}_{\mathrm{M}}\right)$, and coordinates $\left(x_{\mathrm{M}}, y_{\mathrm{M}}, z_{\mathrm{M}}\right)$. The $\mathrm{M}$ coordinate system is solely determined by the orientation of the mine's main-axis $i_{\mathbf{M}}$. The unit vectors of the $\mathrm{M}$ coordinate system are given by (Figures 5 and 6)

$$
\mathbf{j}_{M}=\mathbf{k} \times \mathbf{i}_{M}, \quad \mathbf{k}_{M}=\mathbf{i}_{M} \times \mathbf{j}_{M}
$$

The F-coordinate is represented by $\mathrm{F}_{\mathrm{F}}\left(\mathrm{X}, \mathrm{i}_{\mathrm{F}}, \mathrm{j}_{\mathrm{F}}, \mathrm{k}_{\mathrm{F}}\right)$ with the origin $\mathrm{X}$, unit vectors $\left(\mathrm{i}_{\mathrm{F}}, \mathrm{j}_{\mathrm{F}}, \mathrm{k}_{\mathrm{F}}\right)$, and coordinates $\left(x_{\mathrm{F}}, y_{\mathrm{F}}\right.$, $Z_{\mathrm{F}}$ ). Let $\mathrm{V}_{\mathrm{w}}$ be the fluid velocity. The water-to-shape velocity is represented by

$$
\mathbf{V}_{\mathrm{r}}=\mathbf{V}_{\mathrm{w}}-\mathbf{V} \text {, }
$$

which can be decomposed into two parts,

$$
\mathbf{V}_{r}=\mathbf{V}_{1}+\mathbf{V}_{2}, \mathbf{V}_{1}=\left(\mathbf{V}_{r} \cdot \mathbf{i}_{F}\right) \mathbf{i}_{F}, \mathbf{V}_{2}=\mathbf{V}_{r}-\left(\mathbf{V}_{r} \cdot \mathbf{i}_{F}\right) \mathbf{i}_{F},
$$

where $\mathbf{V}_{1}$ is the component parallel to the shape's main-axis (i.e., along $\mathbf{i}_{\mathrm{M}}$ ), and $\mathbf{V}_{2}$ is the component perpendicular to the shape's main-axial direction. The unit vectors for the Fcoordinate are defined by (column vectors)

$$
\mathbf{i}_{F}=\mathbf{i}_{M}, \quad \mathbf{j}_{\mathrm{F}}=\mathbf{V}_{2} /\left|\mathbf{V}_{2}\right|, \quad \mathbf{k}_{\mathrm{F}}=\mathbf{i}_{\mathrm{F}} \times \mathbf{j}_{\mathrm{F}} .
$$

In the F-coordinate, the hydrodynamic forces (drag, lift) and torques are easily computed ([5] White 1974; [6] Crowe et al. 2001).

\section{B. Momentum Balance}

The translation velocity of the shape $(\mathbf{V})$ is governed by the momentum equation in the E-coordinate system ([1] von Mises 1959)

$$
\frac{d}{d t}\left[\begin{array}{l}
u \\
v \\
w
\end{array}\right]=-\left[\begin{array}{l}
0 \\
0 \\
g
\end{array}\right]+\frac{\mathbf{F}_{b}+\mathbf{F}_{h}}{\rho \Pi},
$$

where $g$ is the gravitational acceleration; $\Pi$ is the shape volume; $\rho$ is the rigid body density; $\rho \Pi=m$, is the shape mass; $\mathbf{F}_{h}$ is the hydrodynamic force (i.e., surface force including drag, lift, impact forces); $\mathbf{F}_{\mathrm{b}}=-\rho_{w} \Pi$, is the

buoyancy force; and $\rho_{w}$ is the water density. The drag and lift forces are calculated using the drag and lift laws with the given water-to-shape velocity $\left(\mathbf{V}_{r}\right)$. In the F-coordinate, $\mathbf{V}_{r}$ is decomposed into along-shape $\left(\mathbf{V}_{1}\right)$ and across-shape $\left(\mathbf{V}_{2}\right)$ components.

\section{Moment of Momentum Equation}

It is convenient to write the moment of momentum equation ([1] von Mises 1959)

$$
\mathbf{J} \bullet \frac{d \boldsymbol{\omega}}{d t}=\mathbf{M}_{b}+\mathbf{M}_{h},
$$

in the M-coordinate system with the shape's angular velocity components $\left(\omega_{1}, \omega_{2}, \omega_{3}\right)$ defined by (4). Here, $\mathbf{M}_{b}$ and $\mathbf{M}_{h}$ are the buoyancy and hydrodynamic force torques. The buoyancy force induces the moment in the $\mathbf{j}_{\mathrm{M}}$ direction if the COM doesn't coincide with the COV (i.e., $\chi \neq 0$ ),

$$
\mathbf{M}_{b}=\Pi \chi \rho_{w} g \cos \psi_{2} \mathbf{j}_{\mathrm{M}} .
$$

The hydrodynamic force $\left(\mathbf{F}_{\mathrm{h}}\right)$ and torque $\left(\mathbf{M}_{\mathrm{h}}\right)$ are easily calculated in the F-coordinate system using existing formulas. After calculation, the hydrodynamic force $\left(\mathbf{F}_{\mathrm{h}}\right)$ should be transformed from the F-coordinate to the Ecoordinate before substituting into the momentum equation (7), and the hydrodynamic torque $\left(\mathbf{M}_{\mathrm{h}}\right)$ should be transformed from the F-coordinate to the M-coordinate before substituting into the moment of momentum equation (8) for solutions (Chu et al. 2004). To compute the hydrodynamic force $\left(\mathbf{F}_{\mathrm{h}}\right)$ and torque $\left(\mathbf{M}_{\mathrm{h}}\right)$, the drag and lift coefficients should be given. For spherical and cylindrical mines, these coefficients can be computed using Reynolds number dependent semi-empirical formulae (Chu et al., 2005, 2006). However, for the operational mine shapes such as Manta or Rockan, there are no such mathematical expressions to use. In this thesis, a Mine Drop Experiment was conducted with operational mine shapes.

\section{Experiment Setup}

\section{A. Preparation}

The overall objective of the experiment, conducted between 12-16 September 2005, was the collection of trajectory data from each of four mine-like shapes. Each shape was dropped just above the surface of the water and filmed with a pair of high-speed cameras as the shape fell through the water column. Each trajectory was then converted to an array of Cartesian coordinates and analyzed with software specifically designed to work with the highspeed cameras.

Mine shapes were selected based upon current and future operational relevance. A collection of four mine-like polyester resin test shapes were used during the experiment phase of the project. These shapes consisted of a Sphere, a semi-hemispherical "Gumdrop" shape, a scale model of the Manta bottom mine, and a scale model of the Rockan bottom mine. The Sphere was selected to serve as a "calibration" shape because its shape symmetry and equal weight distribution about its three axes. The Gumdrop was similar in shape to but higher in density than the Sphere. The Gumdrop was selected to act as a kind of "traditional" 
shape of bottom sea mines, though no mine was specifically represented.

The construction of the test shapes consisted of a three-part production process: prototype development, mold construction and test shape casting \& finishing. This process was necessary to facilitate more efficient experimentation and to reduce the production cost of the experimental test shapes.

Prototype production for all the shapes except the sphere began by taking solid blocks of plaster of Paris and machining the shapes to the properly scaled dimensions and characteristics based on available mine blueprints. Only the shapes of the mines were duplicated, not the internal workings or functions. The sphere prototype was a solid rubber ball with a diameter appropriate to the scale of the other shapes (Tables 3 and 4).

Table 3. Mass and density of model mines.

\begin{tabular}{|l|l|l|l|}
\hline Model & Description & Mass & Density \\
\hline Model 1 & $\begin{array}{l}\text { Generic Sphere } \\
\text { Shape }\end{array}$ & $1692.0 \mathrm{~g}$ & $1.335 \mathrm{~g} / \mathrm{cm}^{3}$ \\
\hline Model 2 & $\begin{array}{l}\text { Gumdrop } \\
\text { Hemispherical } \\
\text { Shape }\end{array}$ & $2815.0 \mathrm{~g}$ & $1.722 \mathrm{~g} / \mathrm{cm}^{3}$ \\
\hline Model 3 & $\begin{array}{l}\text { Manta Bottom } \\
\text { Influence Mine } \\
\text { Shape }\end{array}$ & $1145.0 \mathrm{~g}$ & $1.615 \mathrm{~g} / \mathrm{cm}^{3}$ \\
\hline Model 4 & $\begin{array}{l}\text { Rockan Bottom } \\
\text { Influence Mine } \\
\text { Shape }\end{array}$ & $813.0 \mathrm{~g}$ & $1.388 \mathrm{~g} / \mathrm{cm}^{3}$ \\
\hline
\end{tabular}

Table 4. Geometric features of model mines.

$\begin{array}{lll}\text { Model } & \text { Dimension } & \\ \text { Model } & \text { D: } & 13.0 \mathrm{~cm} \\ 1 & \text { Scale: } & \text { N/A } \\ & \text { Distance from COM to COV: } & \\ & & 0 \mathrm{~cm} \\ \text { Model } & \text { D: } & 14.9 \mathrm{~cm} \\ 2 & \text { H: } & 13.3 \mathrm{~cm} \\ & \text { Scale: } & \text { N/A } \\ & \text { Distance from COM to COV: } & \\ & & 0 \mathrm{~cm} \\ \text { Model } & \text { D(Bottom): } & 15.0 \mathrm{~cm} \\ 3 & \text { D(Top): } & 7.0 \mathrm{~cm} \\ & \text { H: } & 6.2 \mathrm{~cm} \\ & \text { Scale: } & 1 / 6 \\ & \text { Distance from COM to COV: } & \\ & & +0.373 \mathrm{~cm} \text { z-axis } \\ \text { Model } & \text { L: } & 16.0 \mathrm{~cm} \\ 4 & \text { W(Back): } & 7.8 \mathrm{~cm} \\ & \text { W(Front): } & 13.3 \mathrm{~cm} \\ & \text { H(Back): } & 6.3 \mathrm{~cm} \\ & \text { H(Front): } & 3.8 \mathrm{~cm} \\ & \text { Scale: } & 1 / 6 \\ & \text { Distance from COM to COV: } & \\ & & 0 \mathrm{~cm}\end{array}$

Once prototype construction was complete, work began on making casting molds of the prototypes from which the final experimental shapes could be produced. Mold production was identical for all four shapes. The mold making process consisted of making two separate mold halves for a given shape. To create the first half of the mold, a cardboard container was constructed to hold the shape and the molding materials. This container was sealed at all joints, and then filled 2/3 with sand. On top of the sand, a layer of modeling clay was packed and smoothed in the container. The prototype shape was then depressed half way into the clay along its long axis leaving the remaining half of the shape exposed. To facilitate simple removal from the final mold, the exposed portion of the shape, clay and interior of the container were coated with a silicon release agent. After all preparations were complete, the remainder of the box was filled with commercially available liquid urethane rubber molding compound and allowed to cure overnight. It is also worth noting that the particular type of urethane rubber used is of the sort that did not require vacuum degassing to remove bubbles. When the rubber was cured into its final state, the completed mold-half was removed from the container. To create the second half of the mold, the process was repeated, but instead of using sand and clay to support the prototype, the newly created mold half was utilized. After the entire mold was complete, holes were placed in the ends of the mold to facilitate resin insertion and the evacuation of air as the casting material entered the mold. This process was repeated for all remaining prototype test shapes.

The final step in the production of the testing shapes consisted of pouring and finishing the numerous uniform-density polyester resin castings created from the prototype molds. The castings were created from commercially available, two-part, ultra-low viscosity, rigid, urethane casting resin which readily accepts coloring and density additives and yielded virtually bubble-free castings without costly degassing procedures. As possibility of damage to the test facility and personnel was of paramount concern, the resin chosen possessed a shore hardness rating of 70D, which means that the shape would maintain dimensional integrity throughout the flight path, but still pose little risk of damage to the facility were it to impact the wall, window or floor of the test tank at high velocity. To facilitate creation of an accurately scaled model, all portions of the resin mixture were carefully measured and weighed, and fine brass powder was added to the resin during mixing to achieve the proper density ratio. Note: The densities of the Manta and Rockan shapes were based on the average densities of those mines. When all materials were prepared, the rubber mold was coated with silicone release agent, and closed using cloth straps. The resin mixture was then poured into the mold and allowed to cure overnight. When the casting was fully cured, the mold was carefully opened, and the final testing model removed from the mold. The models were allowed to cure an additional 48 hours prior to finishing. Finishing consisted of filling any imperfections with a slurry of polyester resin, followed by sanding and painting. A $150 \mathrm{~g}$ lead weight was placed in the center bottom of the Manta shapes to 
make the center of gravity in the model more accurately represent the Manta mine's lower center of gravity. All models were painted with flat black spray enamel, and a series of white fiducials were added to aid in analysis of the digital video data. This process was repeated for each category of prototype so that at the time of experimentation, there were three testing models of each test shape available. Figures 7-10 show various model mines.
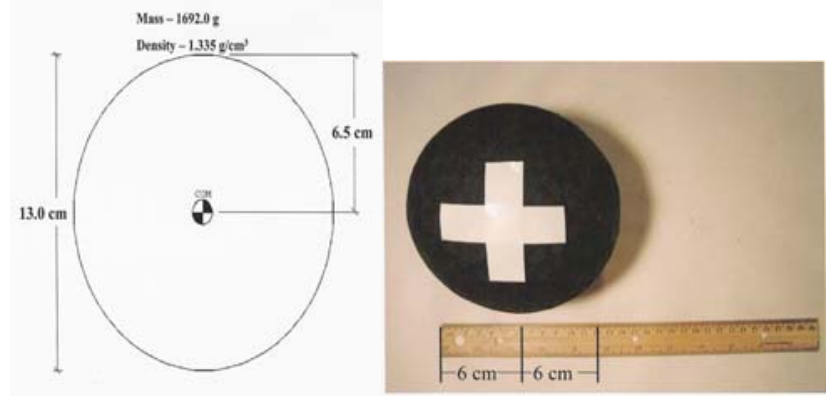

Figure 7. Sphere Shaped Model Mine.

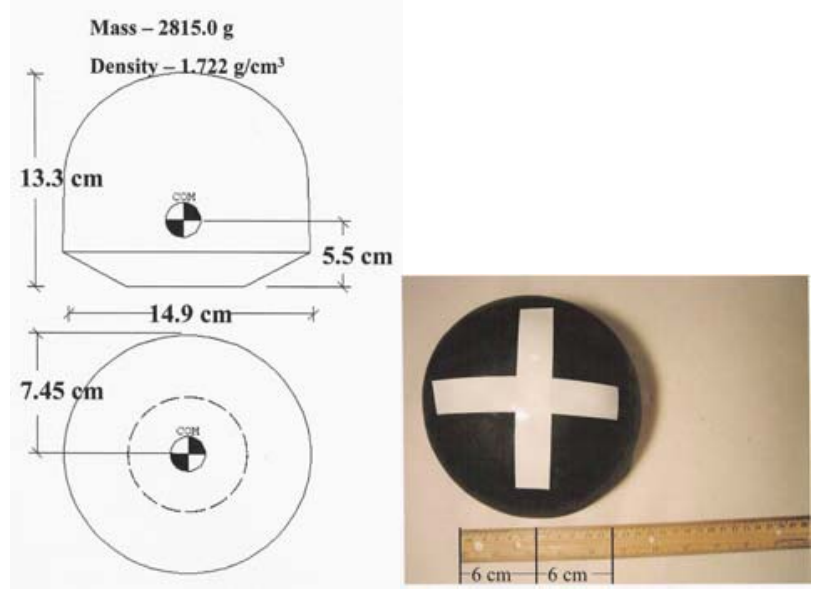

Figure 8. Gumdrop Shaped Model Mine.
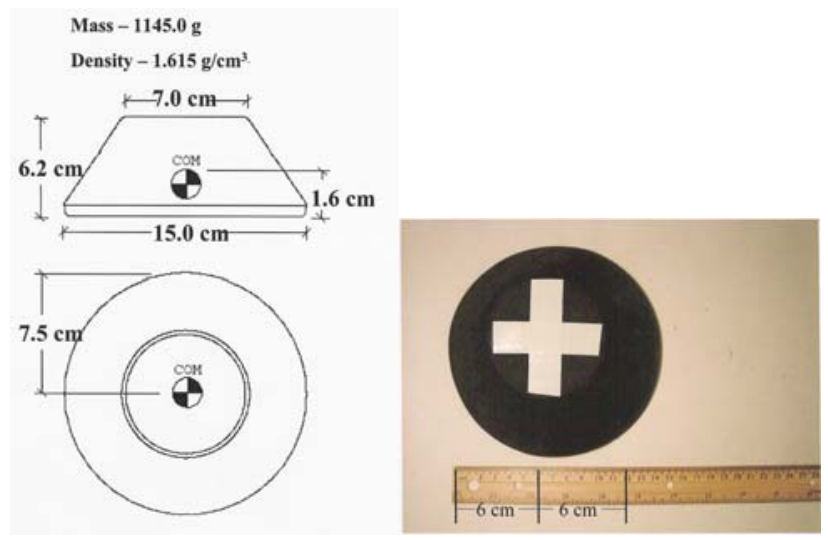

Figure 9. Manta Shaped Model Mine.

\section{B. Release Mechanism}

The drop phase of the experiment consisted of inserting each model into the water at one foot above the water on a nearly vertical slanted board (Figure 11) mounted to the moveable bridge and directly above the focal point of the cameras. When the mine shapes entered the water, they traveled vertically.

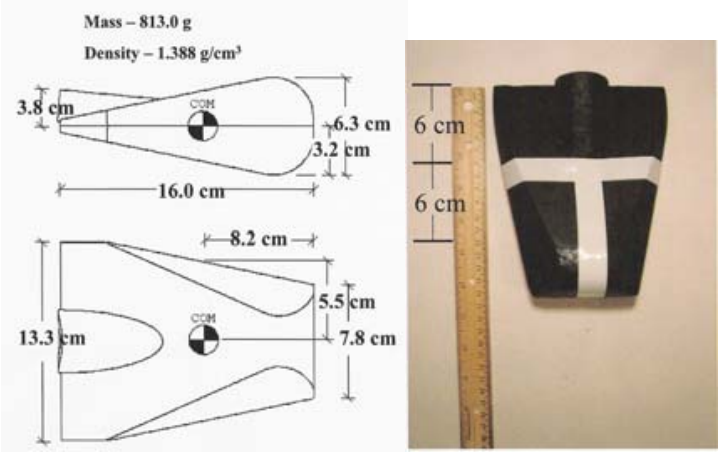

Figure 10. Finished Rockan Shaped Model Mine.

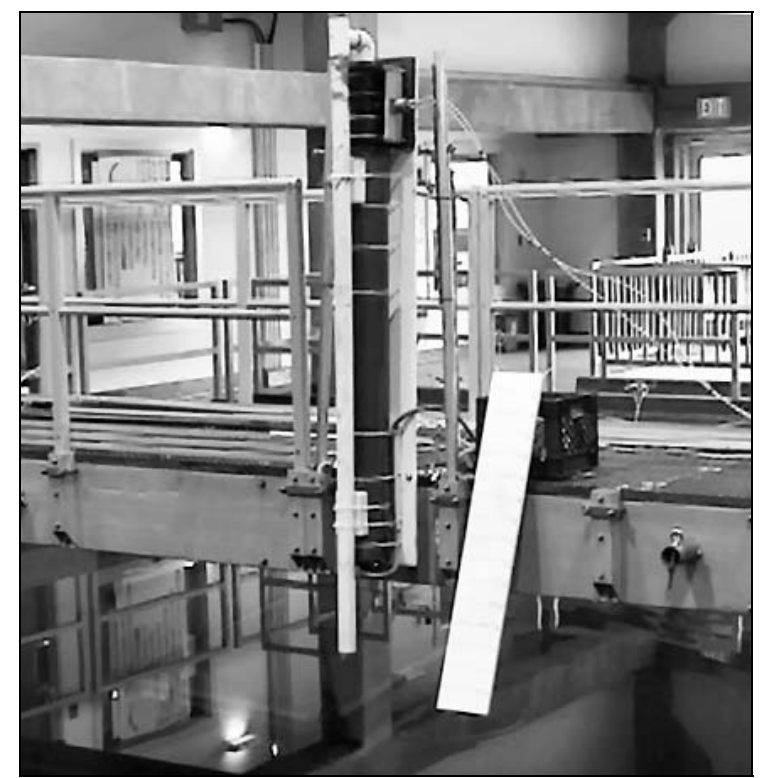

Figure 11. Release Board Mounted on Moveable Bridge.

\section{Test Tank}

MIDEX II was conducted at the Monterey Bay Aquarium Research Institute (MBARI) Unmanned Underwater Vehicle Test Tank (Figure 12). Enclosed inside a large building, this $10 \mathrm{~m} \times 15 \mathrm{~m} \times 10 \mathrm{~m}$ tank was filled with "standard sea water." This water was maintained by an ozone filtration system, with no impurities save the remnants of blue dye placed into the tank several weeks prior to the experiment. The faint blue coloration had no effect on the shape trajectories, but it did 
add some difficulty illuminating the tank. Hence the video data quality was somewhat degraded. A sliding bridge, on which the slanted board was mounted, spanned the width of the tank. Figure 13 describes the measurements of the tank and placement of the drop zone, cameras, and lighting.

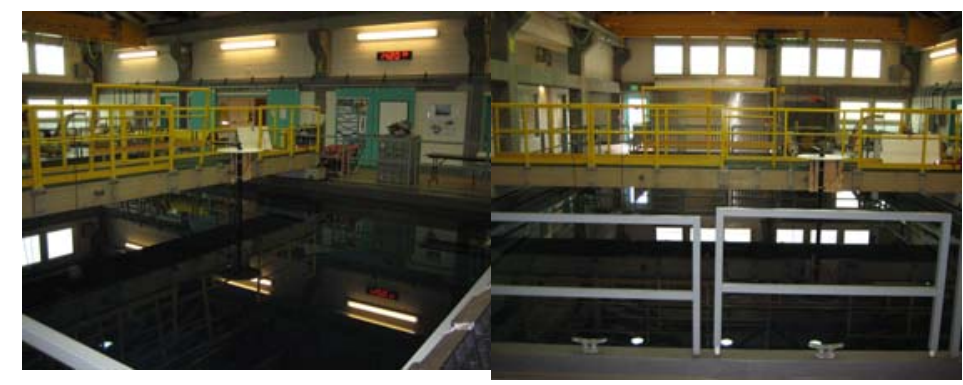

Figgure 12. MBARI Test Tank Facility (Structure Above Water is Moveable Bridge).

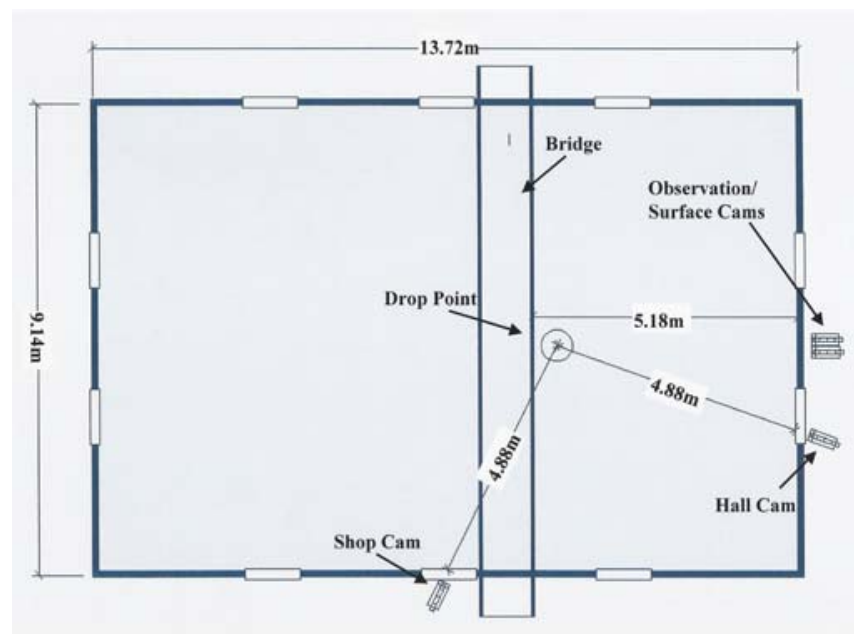

Figure 13. Top view of MIDEX-II setup.

The tank was used to simulate the littoral operating environment with the scaled depth ranging to $54.9 \mathrm{~m}$ (180 foot), however the nature of the viewing windows only allows data collection to a scaled depth of roughly $18.29 \mathrm{~m}$ (60 feet). The tank has no current and no wind blowing over its surface. To aid in shape recovery, a $9 \mathrm{~m} \times 13 \mathrm{~m}$ two-centimeter netting was mounted to a constructed $1.9 \mathrm{~cm}$ diameter PVC piping horizontal grid and placed at the bottom of the tank out of camera view. At the end of a run, the net contained the shapes was retrieved using a series of pulleys placed at the four corners of the tank. Two large, dark blue $4.57 \mathrm{~m} \times 5.18 \mathrm{~m}$ tarpaulins were placed along the tank walls behind the camera views to assist the cameras and software with distinguishing the falling mine shapes from the tank background.

Eight viewing windows (Figure 14), as shown on the tank diagram, were $1.83 \mathrm{~m}$ (6 feet) below the surface of the water. The two viewing windows used were selected because of the unobstructed and near perpendicular view to the drop spot.

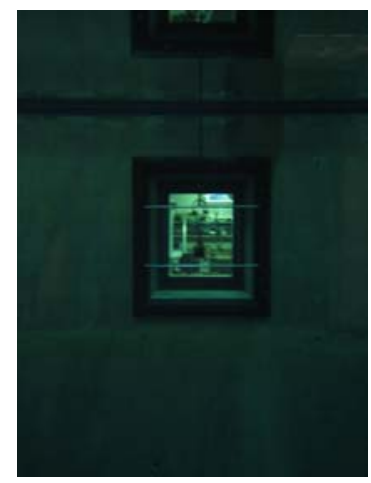

Figure 14. View from Underwater Viewing Window.

\section{Cameras and Data Collection Equipment}

All data was collected digitally using a network of high-speed and standard video equipment and computers. Surface level information collected included experiment data and the video log. This data was collected using a pair of standard commercially available digital video camera, mounted on tripods, and located at the end of the pool directly in front of the testing zone. Both top cameras operated at a $30 \mathrm{~Hz}$ frame rate. The data camera used a narrow view lens zoomed to focus on the area directly between the slanted board and the water surface, and was toggled on and off between test runs. The second camera used a wide-angle lens, and was employed to record a video log of the experiment. This device ran continuously throughout the experiment.

Subsurface video data, used to determine the trajectory of the falling shapes, was collected using a pair of high-speed, Photron FASTCAM PCI digital cameras (Figure 15). These cameras were mounted on tripods in two separate windows, at an angle of $70^{\circ}$ in relation to one another so as to provide two, near orthogonal, views of the drop zone. After mounting and calibration, each camera station was covered with black plastic to block out any light source beside that which came from the field of view. The cameras were synchronized, calibrated and connected by a centrally located laptop computer via high-speed data cables. During testing the cameras were operated using the Photron FASTCAM Viewer software at $512 \times 480$ pixel 
resolution at full frame and recording rates of $125 \mathrm{~Hz}$. To facilitate a wider field of view, both cameras were fitted with wide-angle lens. All data was recorded digitally on a standalone 200 GB hard drive during the test phase. Additionally, to enhance the quality of the data during testing, the installed tank lighting system was turned to its maximum setting and a pair of 1000 -watt high intensity photography lights were mounted and used above the surface.

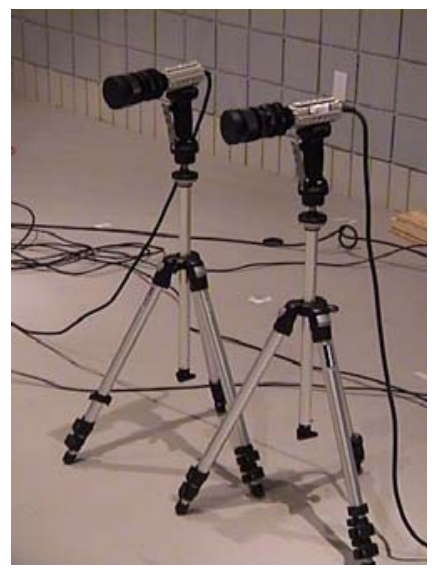

Figure 15. Photron FASTCAM PCI digital camera.

\section{Methodology}

\section{A. Overview}

The mine drop experiment consisted of releasing each shape vertically from $0.3 \mathrm{~m}(1 \mathrm{ft})$ above the surface of the water. The entry of each shape into the water was recorded by the two above-surface video cameras. All subsurface data collection was facilitated by the two FASTCAM PCI high-speed cameras. The subsurface digital data was analyzed by 3-D motion analysis software to determine the trajectories of each shape. All data from runs involving malfunctions was discarded. Overall, the Manta shape was successfully dropped 15 times, the Gumdrop 9, the Rockan 14, and the Sphere 13. Initial velocities of all shapes as they entered the water were calculated later using the MAXTRAQ motion analysis software.

\section{B. Camera Calibration}

Prior to the commencement of testing, calibration images were taken from each underwater camera view. This procedure provided an artificial frame of reference for use by the analysis software in computing the shape's trajectory in the data retrieval phase. To accomplish this task, a geo-referenced calibration target consisting of a white, three-dimensional cross (Figure 16) was lowered into the camera's field of view to a depth of $250 \mathrm{~cm}$ and filmed. The z-axis was determined by the vertical component of the cross, and the two horizontal components were used to acquire the $\mathrm{x}$ - and $\mathrm{y}$-axes. Following acquisition of all calibration images, both cameras were secured to their final position and barricaded to prevent unwarranted disturbance during the testing phase.

\section{Experimental Procedure}

MIDEX II was conducted by two experimenters via handheld walkie-talkies. One stayed on or near the moveable bridge with the shapes. The other was stationed with the high-speed cameras and computer and served to coordinate the filming and retrieval of the subsurface data. For each individual drop, the experimenter below confirmed the readiness of the cameras and prepared the computer to save the appropriate film file. When this was confirmed, he signaled the one above, who turned on the high-wattage tank lighting, selected the designated shape, and held the shape against the slanted board in the "ready" position.

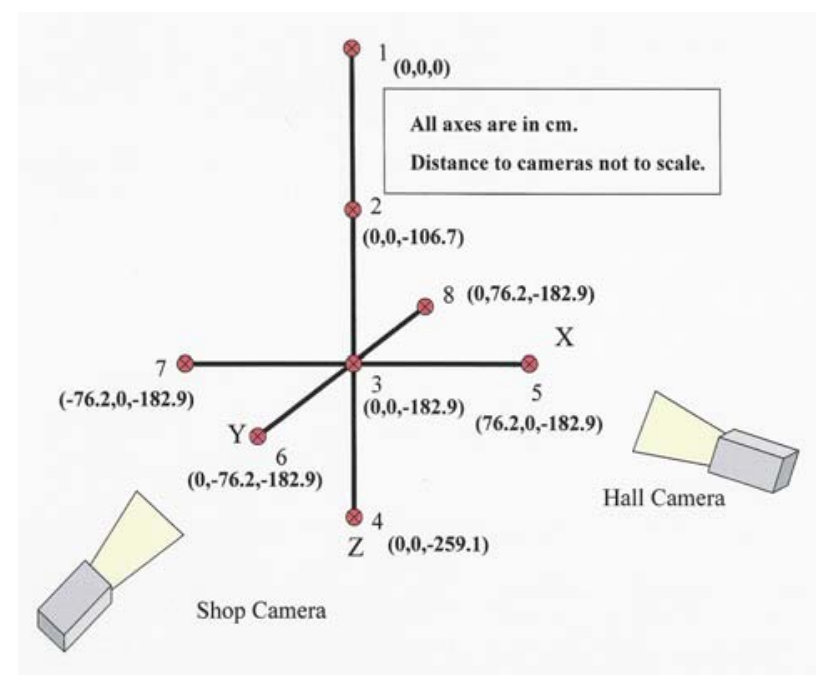

Figure 16. Diagram of Calibration Test Cross.

After a coordinated count conducted via the walkie-talkies, the experimenter at the launch position released the shape as the experimenter below began filming the drop. The shape would then fall from a position of no motion, off the slanted board and into the water surface 0.4 meters below. When the shape fell below the view of both cameras, the cameraman ceased filming, saved the appropriately named file, and again signaled the experimenter above, and then turned off the lighting and note the time and shape in the experimental record notebook. The cycle would then repeat itself until all shapes were dropped. Recovery of the shapes was as described above.

\section{Data Retrieval and Analysis}




\section{A. Data Retrieval}

Data retrieval was accomplished following all experimental test runs by converting the digital video imagery from each drop into an array of x-y-z coordinate data (Figure 17). Commercially available 3-D motion analysis software, MAXTRAQ, was the primary tool utilized to perform this function. Initially, the software was calibrated into the 3-D coordinate reference system utilizing the pairs of calibration images obtained in the initial phase of the experiment. Following calibration, both camera views were time synced and analyzed to determine the actual position of the shape in the $x-y-z$ coordinate field. Frameby frame analysis was performed with the software for each view by manually identifying and inputting one or two marker points associated with the test shape's position. For the Sphere and Gumdrop shapes, one marker point was used to identify the lowest position of the shape. For the Manta shape, marker point \#1 was at the center of the bottom diameter, and marker point \#2 was the center of the top diameter. For the Rockan shape, marker point \#1 was at the center of the narrow edge at the "electronics cylinder," and marker point \#2 was in the center of the thicker edge of the shape opposite marker point \#1. In frames where a marker point was obscured, the position of the marker was estimated visually based on the previous and next viewable frame. Following analysis of both views, the automated functions of the software were employed to compile the 2-D images into a calibrated array of 3-D positional data. This data was saved in an electronic database for use in the final motion analysis and modeling phase of the project. Figure 18 shows a few example screenshots of the MAXTRAQ software in action.

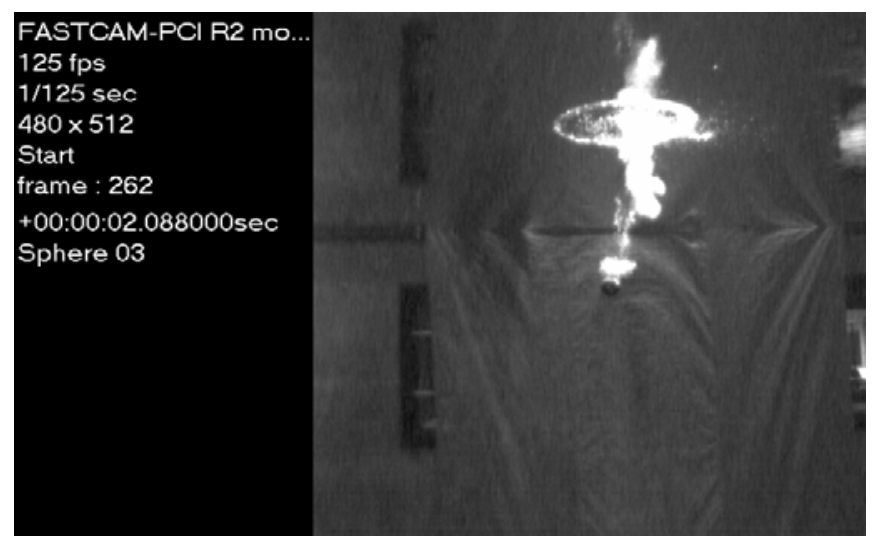

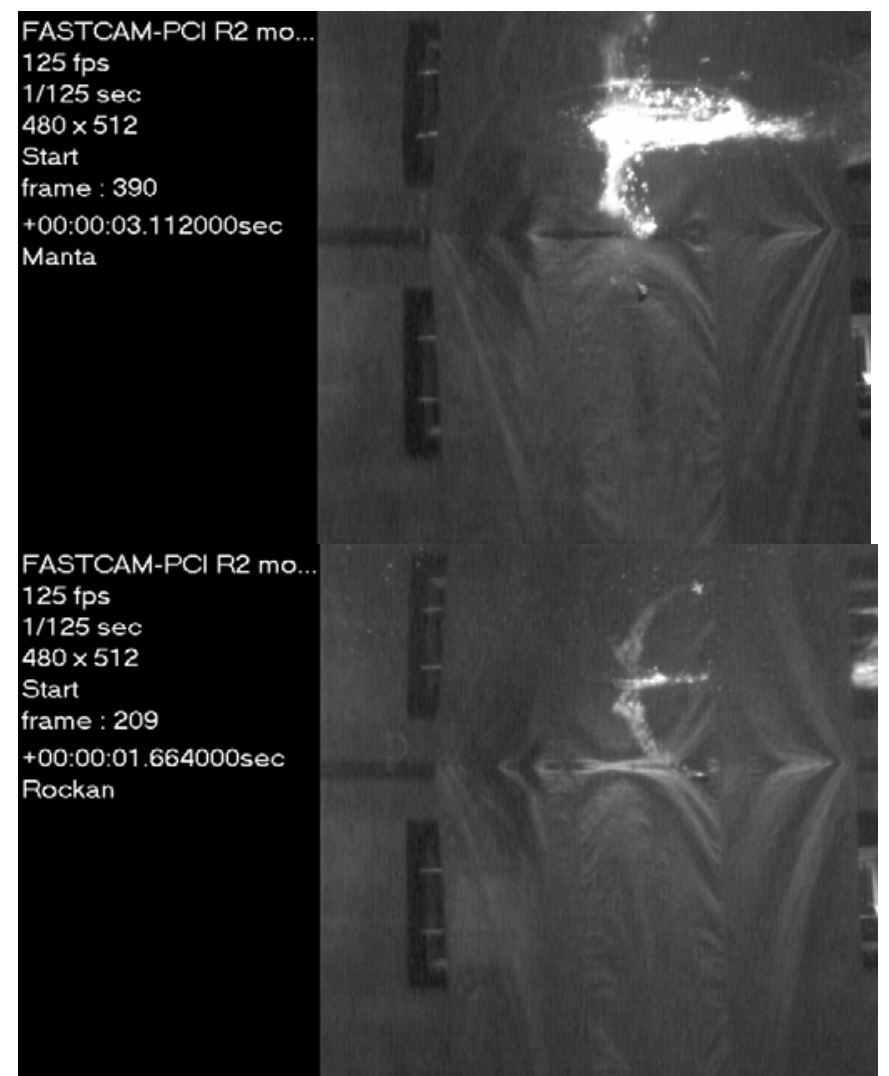

Figure 17. Examples of High Speed Film Frames.

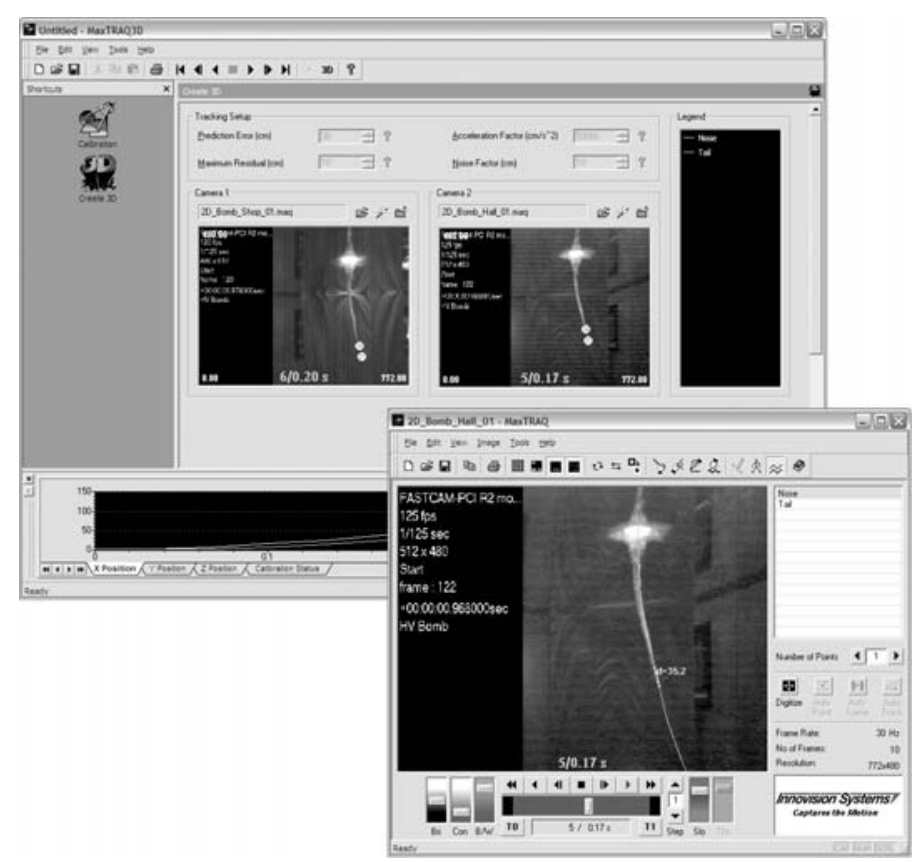

Figure 18. MAXTRAQ analysis software screenshots.

\section{B. Data Analysis}

The three-dimensional coordinate array from each test run was analyzed with specifically designed MATLAB m-files 
used to generate several data plots and reports. In total three plots (x-z, y-z, x-y-z) were used to depict the three dimensional trajectory of the test shape for each run. For the Rockan and Manta, the angle between the two marker points was also calculated to determine the orientation of the shape as it fell (Figure 19). Additionally, a summary of the final positional data point for all test runs at a depth of $2.5 \mathrm{~m}$ was generated (Figure 20).

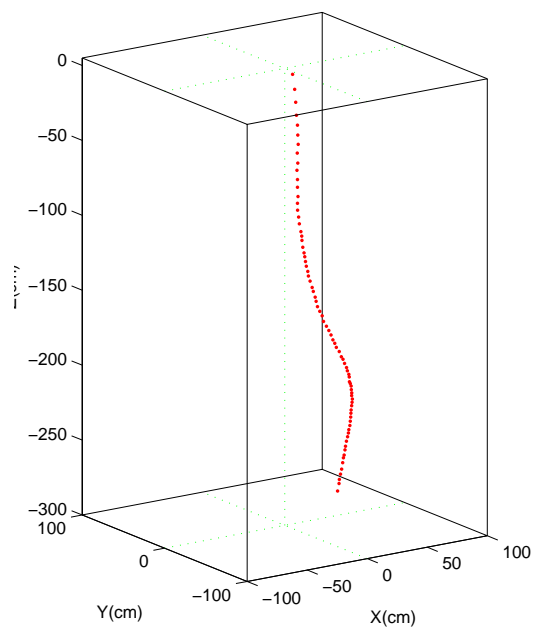

Figure 19. X-Y-Z Trajectory Plot.

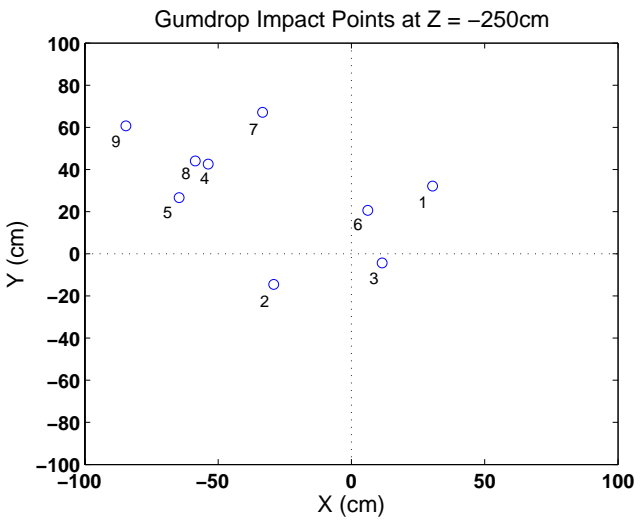

Figure 20. Final Position Data Point Sample.

\section{RESUlts}

\section{A.. Trajectory Patterns}

By analyzing the 2D and 3D plots of each shape drop, general trajectory patterns of each type were developed. Pattern names were based off the generalized path of each shape through the water column. The trajectory patterns are described in Table 5. Examples of each are displayed in Figures 21-23. Appendix A contains all of the 2D and 3D plots.
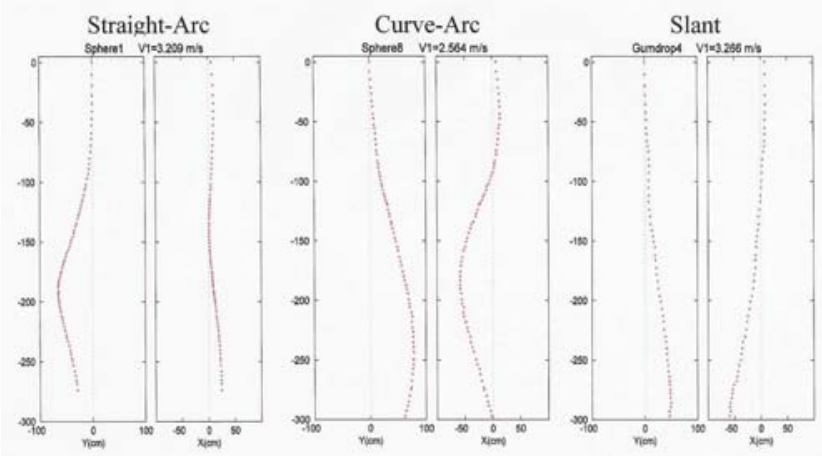

Figure 21. Sphere/Gumdrop Trajectory Examples.

Table 5. Various trajectory patterns.

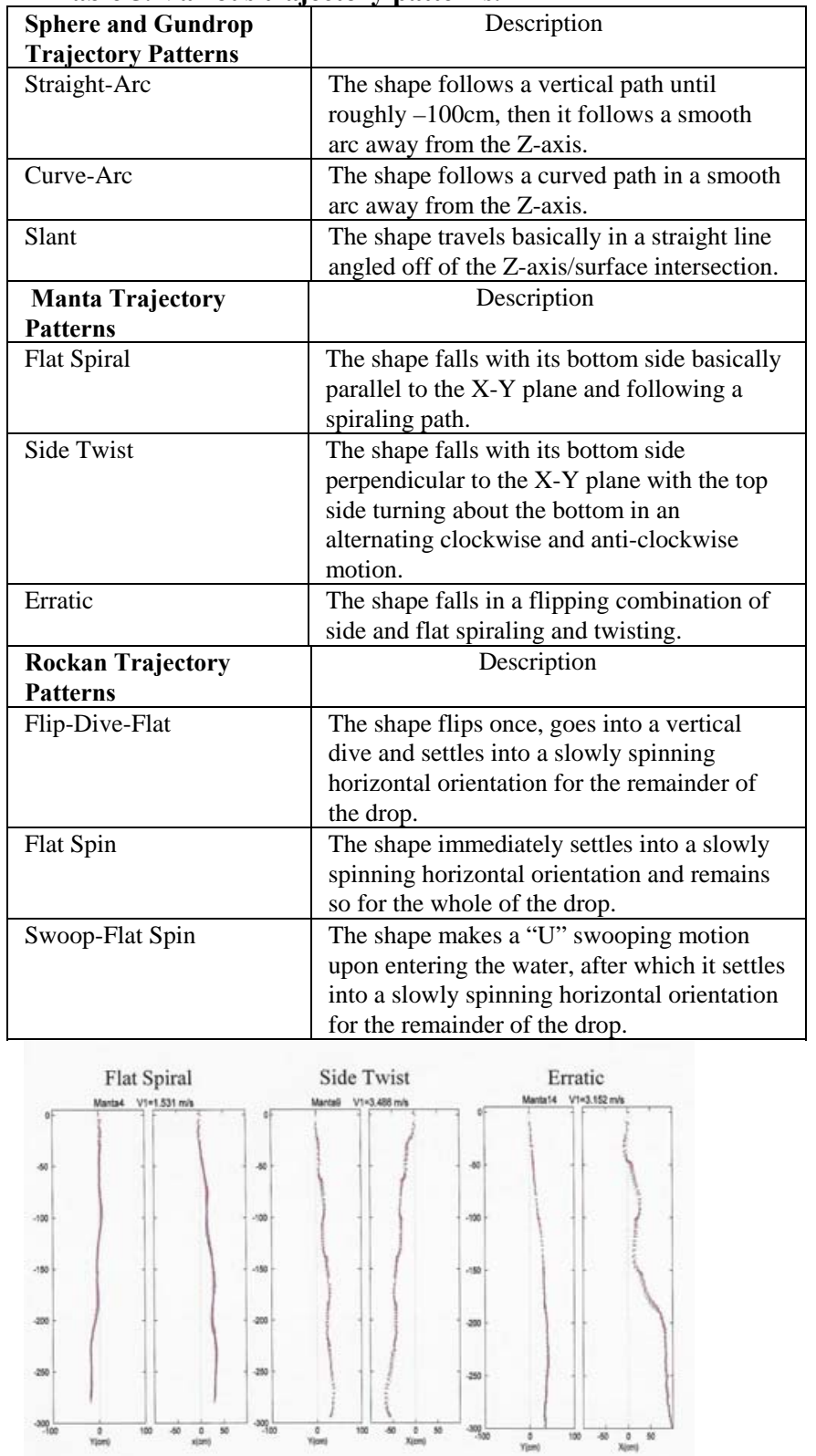

Figure 22. Manta Trajectory Examples. 


$\begin{array}{lllll}\begin{array}{l}\text { Drop } \\ \text { Num } \\ \text { ber }\end{array} & \begin{array}{l}\text { Initial } \\ \text { Velocity } \\ (\mathrm{m} / \mathrm{s})\end{array} & \text { Direction } & \begin{array}{l}\text { Time (s) } \\ \text { at 2.5 } \mathrm{m} \\ \text { depth }\end{array} & \begin{array}{l}\text { Trajectory } \\ \text { Pattern }\end{array} \\ 1 & 1.819 & +\mathrm{X} & 3.360 & \text { Side Twist } \\ 2 & 1.573 & +\mathrm{X} & 3.956 & \text { Flat Spiral } \\ 3 & 2.160 & +\mathrm{X} & 3.248 & \text { Side Twist } \\ 4 & 1.531 & +\mathrm{X},-\mathrm{Y} & 4.800 & \text { Flat Spiral } \\ 5 & 3.116 & + \text { - X, -Y } & 4.040 & \text { Flat Spiral } \\ 6 & 1.653 & - & 4.544 & \text { Flat Spiral } \\ 7 & 1.881 & -\mathrm{Y} & 5.040 & \text { Flat Spiral } \\ 8 & 1.670 & +\mathrm{X} & 4.656 & \text { Flat Spiral } \\ 9 & 3.486 & -\mathrm{X},+\mathrm{Y} & 3.120 & \text { Side Twist } \\ 10 & 2.265 & -\mathrm{X},+\mathrm{Y} & 2.940 & \text { Side Twist } \\ 11 & 2.398 & +\mathrm{X},+\mathrm{Y} & 3.216 & \text { Erratic } \\ 12 & 2.114 & -\mathrm{X},+\mathrm{Y} & 2.816 & \text { Side Twist } \\ 13 & 3.143 & +\mathrm{Y} & 2.928 & \text { Side Twist } \\ 14 & 3.152 & +\mathrm{X},+\mathrm{Y} & 3.176 & \text { Erratic } \\ 15 & 3.199 & -\mathrm{X},+\mathrm{Y} & 3.712 & \text { Erratic } \\ \text { Average } & \mathrm{v} 1 & - & \text { Average Time- } 3.703 & \\ 2.344 & & & & \end{array}$

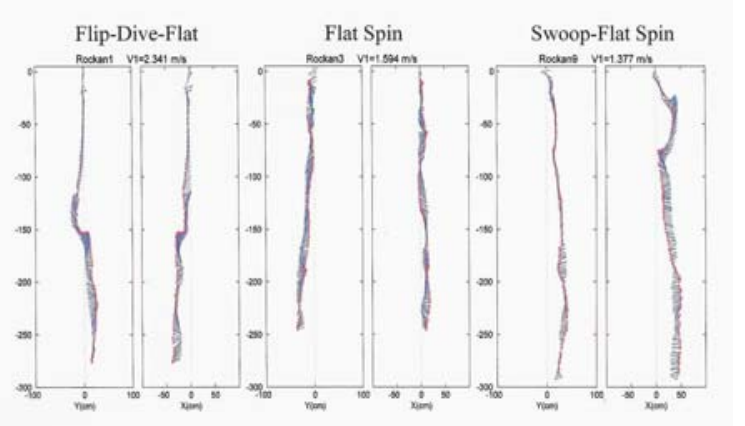

Figure 23. Rockan Trajectory Examples.

Tables 6-10 list the summarized results of all the drops. "Direction" is the general direction away from the Z-axis from which the shape moved.

Table 6. Trajectory patterns for spherical mines.

\begin{tabular}{|l|l|l|l|l|}
\hline $\begin{array}{l}\text { Drop } \\
\text { Number }\end{array}$ & $\begin{array}{l}\text { Initial } \\
\text { Velocity } \\
(\mathrm{m} / \mathrm{s})\end{array}$ & Direction & $\begin{array}{l}\text { Time } \\
(\mathrm{s}) \text { at } \\
2.5 \mathrm{~m} \\
\text { depth }\end{array}$ & \\
\hline 1 & 3.209 & $-\mathrm{Y}$ & 2.272 & Straight-Arc \\
\hline 2 & 3.893 & $+\mathrm{X},-\mathrm{Y}$ & 1.865 & Straight-Arc \\
\hline 3 & 4.050 & $-\mathrm{X},+\mathrm{Y}$ & 1.520 & Straight-Arc \\
\hline 4 & 2.785 & $-\mathrm{Y}$ & 2.096 & Straight-Arc \\
\hline 5 & 3.191 & $+\mathrm{X}$ & 2.008 & Straight-Arc \\
\hline 6 & 3.337 & $+\mathrm{X},+\mathrm{Y}$ & 1.456 & Straight-Arc \\
\hline 7 & 2.965 & $+\mathrm{X},-\mathrm{Y}$ & 1.648 & Straight-Arc \\
\hline 8 & 2.564 & $-\mathrm{X},+\mathrm{Y}$ & 1.984 & Curve-Arc \\
\hline 9 & 3.290 & $+\mathrm{X},+\mathrm{Y}$ & 1.525 & Curve-Arc \\
\hline 10 & 2.898 & $+\mathrm{X}$ & 1.680 & Straight-Arc \\
\hline 11 & 2.789 & $-\mathrm{X},-\mathrm{Y}$ & 1.792 & Curve-Arc \\
\hline 12 & 2.800 & $-\mathrm{X},+\mathrm{Y}$ & 1.696 & Curve-Arc \\
\hline 13 & 3.001 & $+/-\mathrm{X},+\mathrm{Y}$ & 1.808 & Curve-Arc \\
\hline Average v1 3.136 & $\begin{array}{l}\text { Average } \\
1.796\end{array}$ & Time - & \\
\hline
\end{tabular}

Table 7. Trajectory patterns for gumdrop mines.

\begin{tabular}{|l|l|l|l|l|}
\hline $\begin{array}{l}\text { Drop } \\
\text { Number }\end{array}$ & $\begin{array}{l}\text { Initial } \\
\text { Velocity } \\
(\mathrm{m} / \mathrm{s})\end{array}$ & Direction & $\begin{array}{l}\text { Time(s) at } \\
2.5 \mathrm{~m} \\
\text { depth }\end{array}$ & $\begin{array}{l}\text { Trajectory } \\
\text { Pattern }\end{array}$ \\
\end{tabular}

\begin{tabular}{|c|c|c|c|c|}
\hline 1 & 3.730 & $+\mathrm{X},+\mathrm{Y}$ & 1.296 & Curve-Arc \\
\hline 2 & 4.314 & $-Y$ & 1.792 & Straight-Arc \\
\hline 3 & 3.979 & $+\mathrm{X}$ & 1.576 & Straight-Arc \\
\hline 4 & 3.266 & $-\mathrm{X},+\mathrm{Y}$ & 1.344 & Slant \\
\hline 5 & 3.871 & $-X,+Y$ & 1.464 & Slant \\
\hline 6 & 2.603 & $-\mathrm{Y}$ & 1.504 & Curve-Arc \\
\hline 7 & 2.563 & $-\mathrm{X},+\mathrm{Y}$ & 1.472 & Curve-Arc \\
\hline 8 & 2.370 & $-\mathrm{X},+\mathrm{Y}$ & 1.308 & Curve-Arc \\
\hline 9 & 2.206 & $-\mathrm{X},+\mathrm{Y}$ & 1.400 & Curve-Arc \\
\hline \multicolumn{2}{|c|}{ Average v1 - 3.211} & \multicolumn{2}{|c|}{ Average Time -1.462} & \\
\hline
\end{tabular}

Table 9. Trajectory patterns for Manta mines.

Table 10. Trajectory patterns for Rockan mines.

\begin{tabular}{|c|c|c|c|c|}
\hline $\begin{array}{l}\text { Run } \\
\text { Number }\end{array}$ & $\begin{array}{l}\text { Initial } \\
\text { Velocity } \\
(\mathrm{m} / \mathrm{s})\end{array}$ & Direction & $\begin{array}{l}\text { Time(s) at } \\
2.5 \mathrm{~m} \text { depth }\end{array}$ & $\begin{array}{l}\text { Trajectory } \\
\text { Pattern }\end{array}$ \\
\hline 1 & 2.341 & $-\mathrm{X}$ & 4.048 & Flip-Dive-Flat \\
\hline 2 & 2.805 & $+\mathrm{X},-\mathrm{Y}$ & 3.984 & Flip-Dive-Flat \\
\hline 3 & 1.594 & $-Y$ & 5.472 & Flat Spin \\
\hline 4 & 1.066 & $+\mathrm{X},-\mathrm{Y}$ & 5.824 & Swoop-Flat Spin \\
\hline 5 & 1.796 & $+X,-Y$ & 6.176 & Swoop-Flat Spin \\
\hline 6 & 2.213 & $+\mathrm{Y}$ & 4.848 & Flat Spin \\
\hline 7 & 2.597 & $-X,-Y$ & 4.912 & Flip-Dive-Flat \\
\hline 8 & 2.652 & $-\mathrm{Y}$ & 4.880 & Flip-Dive-Flat \\
\hline 9 & 1.377 & $+\mathrm{X},+\mathrm{Y}$ & 4.672 & Swoop-Flat Spin \\
\hline 10 & 2.378 & $+\mathrm{X},+\mathrm{Y}$ & 4.138 & Swoop-Flat Spin \\
\hline 11 & 2.018 & $+X,+Y$ & 4.868 & Swoop-Flat Spin \\
\hline 12 & 2.289 & $+\mathrm{X},+\mathrm{Y}$ & 3.156 & Flip-Dive-Flat \\
\hline 13 & 1.872 & $+\mathrm{X},+\mathrm{Y}$ & 4.740 & Swoop-Flat Spin \\
\hline 14 & 2.362 & $+\mathrm{Y}$ & 3.912 & Swoop-Flat Spin \\
\hline \multicolumn{2}{|c|}{ Average v1 - 2.097} & \multicolumn{2}{|c|}{ Average Time- 4.688} & \\
\hline
\end{tabular}

\section{B. Final Position Plot}

Because the bottom of the test tank was below the camera views, a depth of $2.5 \mathrm{~m}$ was selected as "bottom depth" for purposes of a final position plot (Figure 24). When scaled,

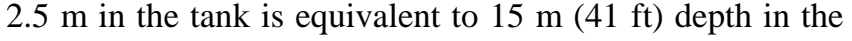
real ocean.

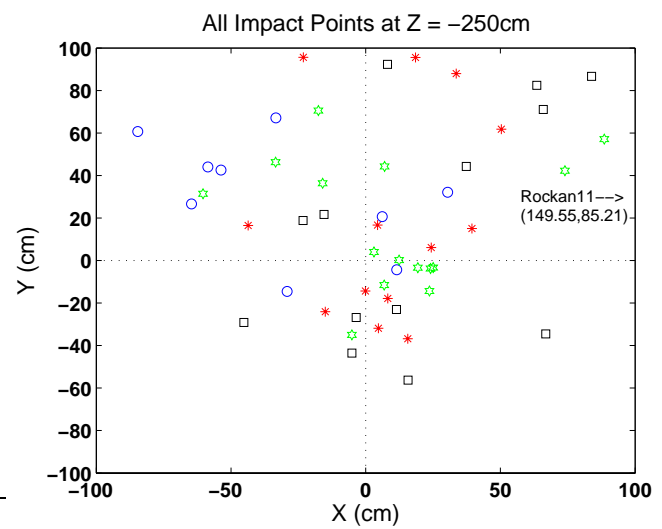

Figure 24. Final Position Plot (All Shapes). Sphere Drop Points are indicated by Red Stars. Gumdrop Drop Points are 
indicated by Blue Circles. Manta Drop Points are indicated by Green Hexagons. Rockan Drop Points are indicated by Black Squares.

\section{DISCUSSION}

\section{A. Shape Trajectories}

It is not surprising that each type of shape seemed to exhibit its own kind of motion. The Sphere and Gumdrop shapes seemed to exhibit generally simple trajectory patterns based on gravity and the shape' rotation about its own axis. Both of those shapes were relatively hydrodynamically smooth, resulting in the quickest drop times in the experiment. The Gumdrop shape had the fastest average time to $2.5 \mathrm{~m}$ depth with 1.462 seconds. The Sphere seemed to favor a Straight-Arc trajectory $(0.62$ probability) over a Curve-Arc one (0.38 probability). The Gumdrop seemed to favor a Curve-Arc (0.56 probability) over both the Straight-Arc (0.22 probability) or simple Slant (0.22 probability).

The Manta shape's bottom-weighted truncated cone was a more complex, less hydrodynamic shape. Hence, it tended to either fall with a Side Twist ( 0.40 probability) or with Flat Spiral (0.40 probability). The remaining runs were Erratic (0.20 probability). The average time, 3.703 seconds, was also over twice that of either the Sphere or Gumdrop shapes.

The Rockan shape was the most complex. Though it was designed to mimic the actual Rockan's ability to smoothly glide through the water, the shape failed to do so in any drop. Instead, it tended to either fall in a Swoop-Flat Spin (0.50 probability) or in a Flip-Dive-Flat (0.36 probability) trajectory. Both of those trajectory types show the potential for Rockan gliding. On two drops (0.14 probability), the shape went directly into a Flat Spin. Because the shape becomes much less hydrodynamic in the vertical when it is at a horizontal angle, the average time to $-250 \mathrm{~cm} \mathrm{Z}(4.688$ seconds) was even greater than the Manta shape. Table 11 summarizes the probabilities for all shapes.

Table 11. Probability of trajectory-pattern occurrence for all mine shapes.

\begin{tabular}{|l|l|l|}
\hline Shape Type & Trajectory Type & Probability \\
\hline Sphere & Straight-Arc & 0.62 \\
\hline (13 total drops) & Curve-Arc & 0.38 \\
\hline & Slant & 0.00 \\
\hline Gumdrop & Straight-Arc & 0.22 \\
\hline (9 total drops) & Curve-Arc & 0.56 \\
\hline & Slant & 0.22 \\
\hline Manta & Flat Spiral & 0.40 \\
\hline (15 total drops) & Side Twist & 0.40 \\
\hline & Erratic & 0.20 \\
\hline Rockan & Flip-Dive-Flat & 0.36 \\
\hline (14 total drops) & Flat Spin & 0.14 \\
\hline & Swoop-Flat Spin & 0.50 \\
\hline
\end{tabular}




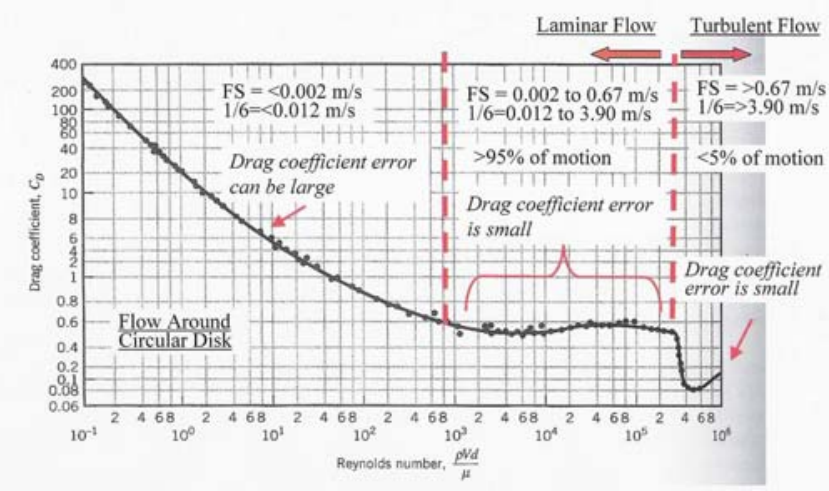

Figure 25. Drag Coefficient vs. Reynolds Number for Flow Around a Circular Disk (After Gefken, 2005).

The Rockan scale model did have a specific trajectory issue independent of its Reynolds number, however. Scaling the Rockan shape to $1 / 6$ the actual size of the operational mine reduced its ability to "glide" through the water as easily as the true Rockan, affecting the "realism" of the Rockan shape trajectory.

\section{Sources of Error}

In MIDEX II, there were errors that hindered determination of the mine shape's exact position and accurate trajectory within the water column. Filming in an underwater environment introduces an inherent degree of parallax distortion above and below the cameras' focal points. This distortion was minimized, however, by first placing the cameras back at the tank wall windows and by using the calibration cross method described previously.

The use of high-speed cameras also introduced shape position tracking difficulty. A higher frame rate per minute necessitated much brighter lighting in the test tank than was available during the experiment. While the water appeared bright and clear on low-speed film, even with the remnants of blue dye in the test tank, the water was much dimmer on the $125 \mathrm{~Hz}$ film. This darkened result made distinguishing the black mine shape from the background more difficult. The darkness problem could not be counteracted with zooming in at the shape's location. Hence, some frames of each fall, especially when a shape was nearer to the bottom of the tank, are almost unreadable.

A shape entering the water also generates an air cavity. Not only can that air pocket greatly affect the initial motion, it also collapses into a stream of obscuring bubbles. The air cavity effect on the motion was minimized buy the low mine shape initial velocities. However, the bubbles from the cavity prohibited automatic tracking via software. In some frames, the mine shape was completed obscured and had to be estimated based on the position of the shape in the surrounding frames.

It should be noted again that all the mine shapes were solid masses made of a resin/bronze powder mixture. As such, the shapes based on the Manta and Rockan mines approximated the shape, average density and COM of the real-world mines. However the shapes did not realistically detail the inner structure, electronics, or explosive distribution of their counterparts. Furthermore, the denser brass powder within the mixture may have "settled" somewhat in the molding process. Settling was minimized by regularly rotating the molds during the hardening process, but the inevitable amount of settling occurring probably resulted in slightly-unsymmetrical weight distribution that affected the trajectory results.

\section{CONCLUSIONS}

MIDEX II is another step in the ongoing process to understand and predict the various parameters that affect a mine's water-phase trajectory. In this case, the primary parameter tested was the mine's shape. Observed trajectories were highly variable, but several broad conclusions can be reached: the Manta and Rockan shapes' trajectories were much more complex than the Sphere and Gumdrop trajectories; the denser Gumdrop shape had the fastest and straightest drops overall to $-250 \mathrm{~cm} \mathrm{Z}$; because of important factors, the dispersion of all four shapes was wide and variable.

Further research and experimentation on mine hydrodynamics is needed. More realistic modeling of the Manta and Rockan mines, to include inner mechanics, electronics, and explosive distribution, should be attempted. Furthermore, scaling the models to a closer size to the actual mines may provide more accurate trajectory patterns, especially in the case of the Rockan. The cost and logistical support of the experiment would increase, but the more realistic results would offset this. Lesser or greater gyrations of the shapes may occur with larger versions.

Changing the conditions of the water column is also an option for further work. Such changes could include but are not limited to generating various currents at different water depths (or conversely, dropping the shapes from a moving platform) or implementing turbulent mixing to simulate coastal processes during the drops.

In any case, the trajectory information gathered in MIDEX II needs to be compared with the results of IMPACT 35 using the same initial conditions. Chaotic features of MIDEX II trajectories should be investigated with instability and predictability analyses. Differences and similarities with IMPACT 35 can then be used to generate "equivalent" cylindrical equations to approximate trajectories of non-cylindrical mines in the next iteration of the IBPM.

\section{Acknowledgments.}

The authors gratefully acknowledge the financial support of the Naval Oceanographic Office (contract number: 
N6230604PO00123) and Office of Naval Research (grant number: N0001405WR20052).

\section{REFERENCES}

Arnone, R.A., and Bowen, Prediction Model of the Time History Penetration of a Cylinder through the Air-Water-Sediment Phases. NCSC Letter Report T34, Naval Coastal Systems Center, Panama City, FL, 1980

Baciocco, A.J., Jr., Technology for the United States Navy and Marine Corps, 2000-2035: Becoming a $21^{\text {st }}$ Century Force, Undersea Warfare, Volume 7. National Academy of Sciences, 1997. (http://www.nap.edu/html/tech_21st/uw2.htm)

Brown, J., Mine Warfare Brief, Defense Technical Information Center. (http://www.dtic.mil/ndia/expeditionary/brown.pdf) 30 January 2006 Chu, P.C., V. Taber, and S.D. Haeger, Environmental Sensitivity Study on Mine Impact Burial Prediction Model. Proc. of the Fourth International Symposium on Technology and the Mine Problem, April 2000, Naval Postgraduate School.

Chu, P.C., A.F. Gilles, C.W. Fan, J. Lan and P. Fleischer, "Hydrodynamics of falling cylinder in water column,” Adv. Fluid Mech., 4, 163-181, 2002a.

Chu, P.C., T.B. Smith and S.D. Haeger, Mine impact burial prediction experiment. Proceedings on the Fourth International Symposium on Technology and the Mine Problem, Naval Postgraduate School, 10 pp., CD Rom, 2002b.

Chu, P.C., C.W. Fan, A. D. Evans, A.F. Gilles, and P. Fleischer, Threedimensional hydrodynamic model for prediction of falling cylinder through water column. DVD-ROM, The OCEANS 2003 MTS/IEEE Conference Proceedings, San Diego, CA, Sept. 22-26, 2003.

Chu, P.C., C.W. Fan, A.D. Evans, and A.F. Gilles, Triple coordinate transforms for prediction of falling cylinder through the water column. $J$. Applied Mech., 71, 292-298, 2004a.

Chu, P.C., C.W. Fan, and A. D. Evans, "Three-dimensional rigid body impact burial model (IMPACT35),” Adv Fluid Mech., 6, 43-52. 2004b.

Chu, P.C., A.D. Evans, A. F. Gilles, T. Smith and V. Taber, "Development of Navy's 3D mine impact burial prediction model (IMPACT35)," Proceedings on the Sixth International Symposium on Technology and the Mine Problem, Naval Postgraduate School, 10 pp., DVD-ROM, 2004c.

Chu, P.C., A. F. Gilles and C.W. Fan, Experiment of falling cylinder through the water column. Exper. Thermal Fluid Sci., 29, 555-568, 2005a.

Chu, P.C., and C.W. Fan, Prediction of falling cylinder through air-water-

sediment columns. J. Appl. Mech., in press 2005b.

Chu, P.C., and C.W. Fan, Pseudo-cylinder parameterization for mine impact burial prediction. J. Fluids Eng., 127, 1515-1520, 2005c.

Chu, P.C., C.W. Fan, A.D. Evans, A. Gilles, T. B. Smith, and V. L. Taber, Development and Verification of 3D Mine Impact Burial Prediction Model (IMPACT35). IEEE J. Oceanic Eng., in revision, 2006.

Crowe, C.T., J.A. Roberson and D.F. Elger, Engineering Fluid Mechanics, $7^{\text {th }}$ Ed., John Wiley \& Sons Inc, New York, 714 pp, 2001.

Department of the Navy. U.S. Naval Mine Warfare Plan Fourth Edition, Programs for the New Millenium. Washington, D.C., January 2006.

(http://www.exwar.org/Htm/ConceptDocs/Navy_USMC/MWP4thEd/ap pendix a.htm) 30 January 2006

Elmore, P.A., R. Wilkens, T. Weaver and M. D. Richardson, IMPACT 28 and 35 simulations of 2003 Baltic Sea cruise: model results and comparison with data. Fifth Annual ONR Workshop on Mine Burial Prediction, Kona, Hawaii, Jan 31 - Feb 2, 2005.

Ashely Evans, Hydrodynamics of mine impact burial. Master Thesis, Naval Postgraduate School, Monterey, CA, CA, 2002 [Co-advised by Peter Fleischer (NAVO)].

Gefken, P., 1/12-Scale Mk84 Model Testing. $8^{\text {th }}$ Joint Classified Bombs/Warheads and Ballistics Symposium, Monterey, California, Aug. 18, 2005.

Gilles, A., Mine Drop Experiment (MIDEX). Master Thesis, Naval Postgraduate School, Monterey, CA, 2001 (co-advised by P.C. Chu and S. Haeger).
Holland, K.T., A.W. Green, A. Abelev and P.J. Valent, "Parameterization of the in-water motions of falling cylinders using high-speed video," Experi. Fluids, 37, 690-770, DOI 10.1007/800348-004-0859-2, 2004.

Hurst, R.B., Mine Impact Burial Prediction Model - Technical Description of Recent Changes and Developments. Defense Scientific Establishment, Auckland, New Zealand, Report 149.

Knudsen, T., Use and Development of Sea Mines, NDRF Summer Conference, 27 August 2004. Powerpoint Presentation.

(http://www.nrdf.dk/documents/groupp/SS04-Knudsen.pdf) 30 January 2006

Lott, D.F., K. Williams, and D. Jackson, Mine Burial in Carbonate Sediments. Proc. of the Technology and Mine Problem Symposium, November 1996, Naval Postgraduate School.

Von Mises, R., Theory of Flight, $1^{\text {st }}$ Ed., Dover Publications Inc., New York, 564-585 pp., 1959.

Satkowiak, L.J., User's Guide for the Modified Impact Burial Prediction Model. NCSC TN 884-87. Naval Coastal Systems Center, Panama City, FL, 1987.

Smith, T.B., Mine Burial Impact Prediction Experiment. Master Thesis, Naval Postgraduate School, Monterey, CA, CA, 2000 [co-advised by P.C. Chu and S. Haeger (NAVO)].

Taber, V.L., Environmental Sensitivity Study on Mine Impact Burial Prediction Model. Master Thesis, Naval Postgraduate School, Monterey, CA, 1999 [co-advised by P.C. Chu and S. Haeger (NAVO)].

White, F.M., Viscous Fluid Flow, McGraw-Hill Inc., New York, 712 pp., 1974. 